\title{
Avaliação do grau de conhecimento de alunos de escolas públicas de dois municípios do interior do estado do Tocantins sobre o conteúdo de Biologia Celular
}

O ensino é caracterizado como um processo universal que apresenta um longo histórico global, sendo de grande importância para a sociedade, na qual a mesma pouco sabe deste fenômeno inerente da ação humana. Dessa forma, compreende-se que o ensino de Ciências Biológicas tem o objetivo de formar alunos críticos, conscientes e embasados, para assim melhor entender o comportamento da sociedade atual. A presente pesquisa tem por objetivo expressar os resultados encontrados por meio da aplicação de um questionário, quanto ao grau de aprendizado dos alunos em sala de aula do ensino de Biologia, visando compreender o motivo que leva ao baixo índice de aprendizado da disciplina e a falta de motivação em conhece-la. Este questionário foi realizado em três escolas no estado do Tocantins, sendo duas no município de Guaraí, e uma no município de Bom Jesus. Concluiu-se, ao fim desta pesquisa, que é de grande relevância que os professores desenvolvam com seus alunos competências capazes de influenciar com o aprendizado dos mesmos, com relação a fortalecer a sua autonomia e a sua identidade na perspectiva de provocar um conhecimento autônomo, significativo e libertador. Nota-se que o ensino da biologia possui grande influência quando relacionada à tecnologia, e isto tem ocasionado muitas mudanças no contexto social, educacional e cultural, o que por sua vez exige que todos os envolvidos tomem novas formas de pensar nos processos de ensino e aprendizagem.

Palavras-chave: Influência da Biologia; História da Biologia; Docência de Biologia; Percepção de Alunos.

\section{Evaluation of the degree of knowledge of students from public schools in two municipalities of the interior of the state of Tocantins on the content of Cellular Biology}

\begin{abstract}
Teaching is characterized as a universal process that presents a long global history, being of great importance to society, in which it knows little of this inherent phenomenon of human action. In this way, it is understood that the teaching of Biological Sciences has the objective of forming critical, conscious and grounded students, in order to better understand the behavior of the current society. The aim of the present research is to express the results obtained through the application of a questionnaire about the degree of learning of students in the classroom of Biology teaching, aiming to understand the reason that leads to the low index of learning of the discipline and the lack motivation to know it. This questionnaire was conducted in three schools in the state of Tocantins, two in the municipality of Guaraí, and one in the municipality of Bom Jesus. It was concluded at the end of this research that it is of great relevance that teachers develop with their students competences capable of influencing their learning, in relation to strengthening their autonomy and their identity in the perspective of provoking an autonomous knowledge, meaningful and liberating. It is noted that biology teaching has a great influence when it comes to technology, and this has caused many changes in the social, educational and cultural context, which in turn requires that all involved take new ways of thinking in the teaching and learning processes and learning.
\end{abstract}

Keywords: Influence of Biology; History of Biology; Biology Teaching; Perceptions of Students.

Topic: Práticas, Didática e Metodologias de Ensino

Reviewed anonymously in the process of blind peer.

Rosineide Coelho Ramos Faculdade Guaraí, Brasil http://lattes.cnpq.br/0143604931899500 rosyrammos@hotmail.com

Rosimeire Coelho Ramos Faculdade Guaraí, Brasil http://lattes.cnpq.br/0324653128079600 rosimeire.coelho.3@gmail.com

Vânia Ribeiro de Souza Faculdade Guaraí, Brasil http://lattes.cnpq.br/4534988774870527 vaniskety4v@gmail.com

\author{
Daniel Dias Lopes \\ Faculdade Guaraí, Brasil \\ http://lattes.cnpq.br/7629359984769327 \\ mateussant563@gmail.com \\ Gesimar Vieira de Mesquita \\ Faculdade Guaraí, Brasil \\ http://lattes.cnpq.br/94765443585584314 \\ gesimarmesquita@hotmail.com \\ Ana Paula Martins Guimarães \\ Faculdade Guaraí, Brasil \\ http://lattes.cnpq.br/5309168123830683 \\ biologa.apmg@gmail.com
}

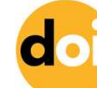

DOI: 10.6008/SPC2318-3047.2017.002.0003
Referencing this:

GUIMARÃES, A. P. M.; LOPES, D. D.; MESQUITA, G. V.; RAMOS, R. C.; RAMOS, R. C.; SOUZA, V. R.. Avaliação do grau de conhecimento de alunos de escolas públicas de dois municípios do interior do estado do Tocantins sobre o conteúdo de Biologia Celular. Educationis, v.5, n.2, p.24-33, 2017. DOI: http://doi.org/10.6008/SPC2318-

3047.2017.002.0003 


\section{INTRODUÇÃO}

Segundo Sousa et al. (2014) o ensino é caracterizado como um processo universal, que apresenta um longo histórico global, sendo de grande importância para a sociedade, na qual, a mesma pouco sabe desse fenômeno inerente da ação humana. Contudo, a educação brasileira foi marcada pela decadência do ensino público na década de 1980, onde nesta época as escolas precisavam de verbas para reformas e compras de matérias, que eram necessárias para o ensino (TEIXIERA et al., 2012).

Para que o professor da disciplina consiga repassar este conhecimento aos alunos, é necessário que apresente uma ampla capacitação em relação a assuntos específicos da Biologia e utilize materiais didáticos e pedagógicos (FONSECA, 2010). Compreende-se que o ensino de Ciências Biológicas tem o objetivo de formar alunos críticos, conscientes e embasados para assim melhor entender o comportamento da sociedade atual.

O ensino de ciências é constituído por princípios teóricos e metodológicas, que estão sempre sujeitos a transformações (AUGUSTO et al., 2007). Devido a isso, o desenvolvimento de metodologias para acesso ao conhecimento científico é de grande relevância. Assim, cabe ao professor o papel de organizar e estabelecer os critérios e estratégias pedagógicas de como irá ministrar a sua aula, e como irá orientar os seus alunos sobre os fatos e fenômenos estudados. Na maioria dos casos, mesmo com a necessidade de construção do conhecimento para a positividade do ensino, muitos professores ainda utilizam unicamente e exclusivamente a forma tradicional de ensinar, sem se preocupar com a utilização do método científico, isto é, fazer com que o aluno seja agente do processo e não meramente um expectador (SOUSA et al., 2014).

Possobom et al. (2010) afirmam que o modelo tradicional de ensino é muito utilizado por diversos professores nas escolas de ensino médio e fundamental. Este modelo de ensino trata o conhecimento como um conjunto de informações que são simplesmente transmitidas pelos educadores para os alunos, o que muitas vezes não resulta em um bom aprendizado (POSSOBOM et al., 2010). Por várias vezes, os alunos fazem o papel unicamente de ouvintes, e o conhecimento que é lhes repassado pelos professores pode não estar sendo absorvidos por estes discentes, são unicamente memorizados por pouco tempo, com isso, geralmente são esquecidos em poucas semanas ou meses, o que comprova que este ensino não é de qualidade para um verdadeiro aprendizado (PAIVA, 2014).

Portanto, é necessário que o professor em suas aulas incentive um dialogo aberto, em que os alunos e o professor tenham uma boa relação, vendo um ao outro como agentes de mudanças que poderia trazer melhorias ao ambiente escolar (NOCOLA et al., 2016). E com isso proporcionando uma qualidade no processo de ensino aprendizagem, tornando-o mais efetivo, envolve-se de forma correta o aprendizado e os modos de participação permitidos e incentivados por órgãos educacionais (BEZERRA et al., 2017).

Estes problemas envolvendo metodologias de ensino que podem facilitar a absorção dos conteúdos está presente em todas as disciplinas de um escola, principalmente nos conteúdos da biologia que, de acordo com Moura et al. (2013), a biologia é conceituada como uma grande área da ciência que estuda os mecanismos de regulação dos organismos e as interações dos seres vivos com o meio ambiente. Portanto, 
pode perceber a real importância e aplicabilidade dessa ciência, quando entendida pelo individuo, o mesmo tem a condição de se posicionar de forma coerente, frente a temas diversos da sociedade moderna. Este aprendizado irá possibilitar ao aluno a capacidade de assimilar, refletir, criticar e aprofundar seu aprendizado em relação aos processos biológicos e com isso entender a relevância dos mesmos na construção de tecnologia que irão gerar produtos que irar beneficiar a sociedade (MOURA et al., 2013).

É necessário que o professor de biologia esteja atualizado, a fim de que a problemática do ensino e da aprendizagem seja menor através do domínio dos temas relacionados à área (NICOLA et al., 2016). É visto que os professores de biologia são constantemente expostos a situações que demandam um posicionamento critico e discussões sobre assuntos complexos e polêmicos como, por exemplo, o cultivo de células tronco e alimentos transgênicos (BAPTISTA et al., 2017). Com isso, dá-se a importância de discutir sobre o ensino da biologia, pois muitas vezes este ensino possui um caráter pouco incentivador e desafiador para os educandos em função de uma prática de ensino desvinculada da realidade, o que poderia ser pela falta de estimulação do pensamento crítico, restrição de conteúdos, vários motivos que podem ocasionar o ensino passivo e desprovido de contextualização (MOURA et al., 2013).

Diante das informações citadas acima, a presente pesquisa tem por objetivo expressar os resultados encontrados por meio da aplicação de um questionário, quanto ao grau de aprendizado dos alunos nas aulas de biologia, visando assim compreender o motivo que leva ao baixo índice de aprendizado da disciplina e a falta de motivação de conhece-la.

\section{METODOLOGIA}

\section{Municípios de aplicação dos questionários}

Este questionário foi realizado em três escolas no estado do Tocantins, duas no Município de Guaraí, Tocantins e uma no município de Bom Jesus, Tocantins. De acordo com o IBGE (2016) o Município de Guaraí, Tocantins está situado na Mesorregião Ocidental do Tocantins e Microrregião de Miracema do Tocantins, possui uma população estimada em 25.642 de habitantes, com coordenadas geográficas: $8^{\circ} 50^{\prime} 03^{\prime \prime}$ de latitude, $48^{\circ} 30^{\prime} 37^{\prime \prime}$ de longitude e altitude de $259 \mathrm{~m}$, sede da 60 Região Administrativa do Estado. Sua densidade demográfica calculada em 2010 pelo IBGE é de 10.23 de habitantes por km².

Ainda segundo dados do IBGE (2016) Bom Jesus do Tocantins está localizado à margem direita do Rio do Sono, na confluência com o Tocantins. Com uma população de 15.246 habitantes, sua densidade demográfica é de 5,4 habitantes por $\mathrm{Km}^{2}$ no território do Município. O município se estende por 2.816,5 Km², está situado a $157 \mathrm{~m}$ de altitude, possui $45^{\circ} 22^{\prime} 60^{\prime \prime}$ latitude S, e longitude de 4836'36" O.

Os colégios que foram realizados os questionários desta pesquisa foram o Orquelina Torres, localizado em Guaraí, que escola possui um tipo de ensino médio que funciona séries do 1ㅇ ao 3o ano, possuindo ensino integral; o colégio Irineu Albano Hendeges, também localizado em Guaraí, que possui um 
ensino médio e fundamental na instituição; e a Escola Estadual Alfredo Nasser localizado no Município de Bom Jesus do Tocantins. Possui um ensino fundamental e médio na instituição.

A escolha das turmas de terceiro ano do ensino médio da rede pública destas três escolas citadas acima, no intuito de observar qual o grau de dificuldades dos alunos em relação à matéria de biologia, sabendo que o aprendizado de biologia é de grande relevância para estes alunos formarem seus conhecimentos críticos e formação como cidadãos.

\section{Elaboração e aplicação do questionário}

O questionário utilizado para o levantamento dos dados foi elaborado pelos autores do presente trabalho, no intuito de desenvolver perguntas que estimulam os alunos a responder sobre o seu conhecimento de biologia, se o mesmo tem interesse na matéria e se o professor ministra bem o conteúdo e quais os materiais que são utilizados para ministrar a aula. É considerado de suma importância a versatilização dos materiais didáticos escolhidos pelo professor para o ensino da matéria em questão.

O questionário foi elaborado seguindo as recomendações de Gil (2002) com adaptações. O estudo de campo constitui o modelo clássico de investigação no campo da Antropologia, onde foi originado. A utilização do mesmo é dada por meio de outros domínios, como na sociologia, educação, saúde publica e na administração (GIL, 2002). Esta pesquisa trata-se de uma pesquisa de campo. Foram utilizados para demonstração dos resultados gráficos e tabelas que foram elaborados com uso do Excel.

O questionário continha 13 questões com perguntas objetivas, e alternativas de multiplaescolha. As perguntas eram relacionadas ao conhecimento da matéria e em relação ao conhecimento do professor da disciplina de biologia, visando em saber qual o grau de dificuldade, conhecimento e interesse do aluno pelos conteúdos ministrado.

A aplicação deste questionário no Colégio Oquerlina Torres ocorreu no dia 05 de outubro de 2017, e no Colégio Irineu Albano e no Alfredo Nasser em 03 de outubro de 2017, sendo realizados em 2 dias (um em uma escola e outro em duas escolas), realizado em apenas uma aula, permitida pelo regente da disciplina. 0 critério utilizado para a escolha dos alunos do terceiro ano do ensino médio da rede pública foram os estudantes com possível curso de graduação já definido, no intuito de observar qual o interesse dos mesmos pela biologia. De acordo com Chaer (2011) a coleta de dados tem o objetivo de encontrar respostas a respeito de um determinado problema que as vezes não possui informações concretas para solucioná-lo. Dessa forma, essa coleta de dados é fundamental para a obtenção de sucesso na realização da pesquisa científica.

Segundo Oliveira et al. (2010), a coleta de dados é considerada um dos momentos cruciais da realização de uma pesquisa, porque é durante esta coleta de dados que o pesquisador obtém as informações necessárias para o desenvolvimento do seu estudo. Segundo Lakatos (2003), a pesquisa de campo é aquela utilizada com o objetivo de conseguir informações ou conhecimentos com relação a um problema, para o qual se procura uma resposta ou de uma hipótese, que se queira comprovar, e ainda descobrir novos fenômenos ou as relações entre eles. 


\section{RESULTADOS E DISCUSSÃO}

No Colégio Orquelina Torres, o questionário foi realizado em 4 turmas para 120 alunos. No Colégio Irineu Albano, foi uma turma, na qual 17 alunos responderam ao questionário. Já no Colégio Bom Jesus, também tivemos uma turma com 28 alunos. Os questionários aplicados nos 3 colégios para os alunos responderam foram iguais. Ao fim do questionário, foram obtidos os seguintes resultados mostrados nas tabelas e gráficos.

Tabela 1: Resultados das questões de 1 a 5 que constavam no questionário aplicado aos alunos dos Colégios Estaduais de Guaraí e Bom Jesus.

\begin{tabular}{|c|c|c|c|c|}
\hline Questão & Alternativa & Oquerlina Torres & Irineu Albano & Alfredo Nasser \\
\hline \multirow[t]{2}{*}{1} & Sim & $100 \%$ & $100 \%$ & $100 \%$ \\
\hline & Não & $0,0 \%$ & $0,0 \%$ & $0,0 \%$ \\
\hline \multirow{3}{*}{2} & Sim & $58 \%$ & $41 \%$ & $29 \%$ \\
\hline & Não & $6 \%$ & $11 \%$ & $26 \%$ \\
\hline & +ou - & $36 \%$ & $48 \%$ & $45 \%$ \\
\hline \multirow[t]{2}{*}{3} & Sim & $98 \%$ & $100 \%$ & $99 \%$ \\
\hline & Não & $2 \%$ & $0,0 \%$ & $1 \%$ \\
\hline \multirow{4}{*}{4} & Sim & $4 \%$ & $0,0 \%$ & $7 \%$ \\
\hline & Não & $69 \%$ & $11 \%$ & $48 \%$ \\
\hline & Nunca & $21 \%$ & $70 \%$ & $26 \%$ \\
\hline & Às vezes & $6 \%$ & $19 \%$ & $19 \%$ \\
\hline \multirow{5}{*}{5} & Bom & $48 \%$ & $41 \%$ & $36 \%$ \\
\hline & Ótimo & $38 \%$ & $12 \%$ & $32 \%$ \\
\hline & Regular & $13 \%$ & $47 \%$ & $32 \%$ \\
\hline & Ruim & $0 \%$ & $0 \%$ & $0 \%$ \\
\hline & Péssimo & $1 \%$ & $0 \%$ & $0 \%$ \\
\hline
\end{tabular}

De forma geral, os alunos dos 3 colégios trabalhados possuem um conhecimento considerado mediano quanto aos conceitos sobre células e apresentaram um conhecimento deficiente, quanto ao mecanismo de funcionamento e as estruturas celulares;

As questões de 1 a 5 como mostra na tabela 1, trata de um questionamento aos alunos quanto ao professor de biologia se era qualificado para ministrar a matéria, se os discentes gostam da disciplina de biologia, se o mesmo acredita que a biologia pode influenciar no seu aprendizado, e por fim como o aluno avalia a qualificação do seu professor e se o mesmo ministra aulas práticas na matéria de biologia;

Os resultados expressos pelos alunos das 3 escolas quanto a questão número 1, que diz respeito a qualificação dos professores de biologia para ministrar aula desta disciplina, $100 \%$ dos alunos disseram que o seu professor de biologia é capacitado. Com relação à questão número $2,75 \%$ dos alunos responderam que gostam da disciplina de biologia. $97 \%$ dos alunos, diz acreditar que a biologia é importante para seu aprendizado de acordo com a questão 3 . De todos os alunos que responderam ao questionário, $77 \%$ responderam com relação à questão de número 4 que os professores ministram aulas práticas na biologia. Por fim, $76 \%$ dos alunos avaliaram em Bom a qualificação dos professores de biologia em ministrar a matéria de acordo com a questão de número 5.

Estes resultados estão de acordo com o encontrado por Malafaia et al., (2010) em seu trabalho intitulado "Análise das concepções e opiniões de discentes sobre o ensino da biologia", no qual a maioria dos alunos consideraram o ensino dos professores de biologia qualificados, mas os docentes sentem a necessidade de ter as aulas práticas para facilitar o ensino da matéria, observando a necessidade de incluir a 
prática docente e disseminação de informações que tornem mais claro e abrangente o real significado da disciplina.

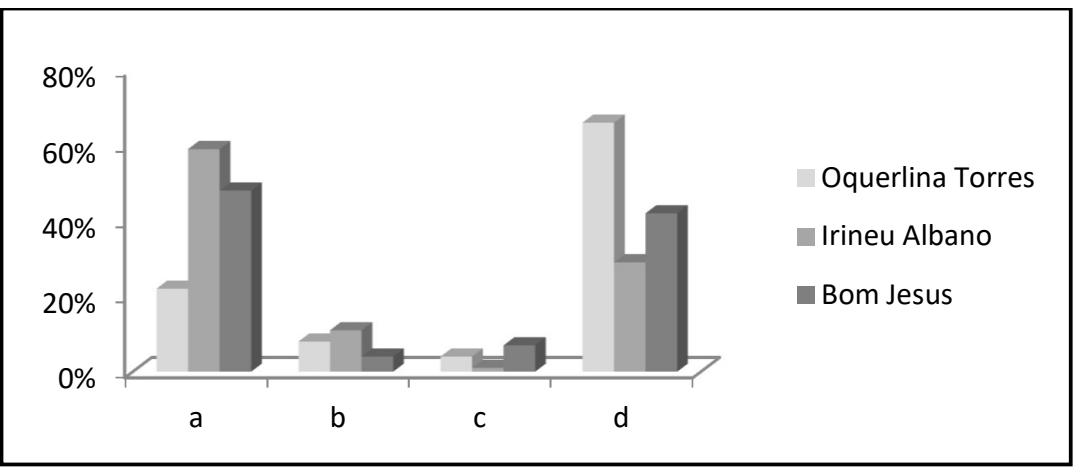

Figura 1: Representação em porcentagem das respostas da questão 6 do questionário aplicado aos alunos dos 3 Colégios trabalhados em Guaraí e Bom Jesus, que trata da concepção dos alunos sobre o termo "biologia".

Na figura 1, que foi exposto o resultado da questão 6, onde os alunos foram questionados nas 3 escolas, qual era o pensamento deles ao ouvir falar em biologia. Nas alternativas de A a D foram propostos temas de estudos sobre a matéria como animais e plantas, experimentos feitos em laboratórios, temas sobre sexo, células e seres vivos, estes temas geralmente são transmitidos aos alunos ao longo do estudo da biologia na escola.

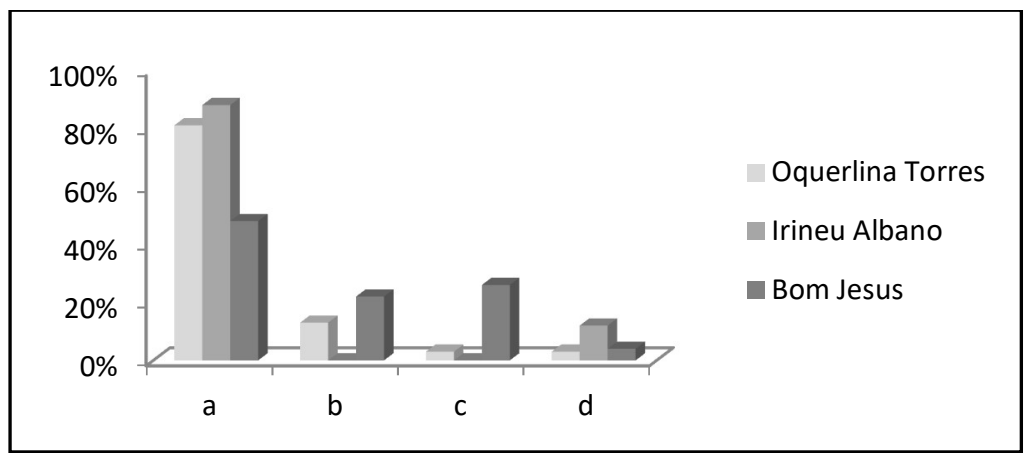

Figura 2. Expressão das respostas obtidas a partir dos questionários aplicados aos alunos dos 3 Colégios pesquisados sobre a concepção de biologia celular.

Os resultados expressos pelos alunos das 3 escolas quanto a questão número 6, que diz respeito aos pensamentos dos estudantes em relação a biologia, $87 \%$ dos alunos disseram relacionar a biologia a células e seres vivos. Em um trabalho semelhante de Bitencourt (2011) em que foram analisados conhecimentos de estudantes sobre a biologia, a maioria diz relacionar a matéria a células, plantas e seres vivos. Estes resultados estão de acordo com o encontrado por Castro et al., (2012), em seu trabalho intitulado "O perfil do conhecimento sobre seres vivos pelos estudantes da COOPEC: uma ferramenta para planejar o ensino de ciências", no qual a maioria dos alunos entrevistados mostrou grande interesse pelo ensino de células e seres vivos, com relação ao formato das células que eles podem observar ao microscópio, fazendo até comparações delas com objetos e animais. Na figura 2, na qual foi exposta a questão 7 , em que se questionou aos alunos das 3 escolas qual era o entendimento do mesmo sobre a citologia. Nas alternativas, propusemos a escolha entre estudos de células, de seres vivos, plantas ou do espaço extraterrestre, esses estudos foram classificados da letra A a letra D. 
Os resultados expressos pelos alunos das 3 escolas quanto a questão número 7, que diz respeito sobre o entendimento dos estudantes com relação a citologia $90 \%$ dos alunos responderam entender que a citologia estar relacionada a estudo de células. Estes resultados estão de acordo com o encontrado por Calixto (2015) em seu trabalho intitulado Discussão sobre contextualização no ensino da citologia considerando a percepção de alunos da educação de jovens e adultos, onde uma parte dos alunos escolheram as respostas de acordo com o conhecimento prévio que tinham do assunto de citologia, mas outra parte apresentou uma dificuldade no aprendizado desta matéria, muitas vezes o fator principal deste desfite pode ser o ensino confuso do professor.

Tabela 2. Resultados das questões de 8 a 12, que constavam no questionário aplicado aos alunos dos Colégios Estaduais de Guaraí e Bom Jesus, sobre o que acreditam que seria necessário para que as aulas de biologia se tornassem atrativas.

\begin{tabular}{|c|c|c|c|c|}
\hline Questão & Alternativa & Oquerlina Torres & Irineu Albano & Alfredo Nasser \\
\hline \multirow[t]{2}{*}{8} & Sim & $98 \%$ & $100 \%$ & $99 \%$ \\
\hline & Não & $2 \%$ & $0,0 \%$ & $1 \%$ \\
\hline \multirow[t]{2}{*}{9} & Sim & $99 \%$ & $100 \%$ & $100 \%$ \\
\hline & Não & $1 \%$ & $0,0 \%$ & $0,0 \%$ \\
\hline \multirow[t]{2}{*}{10} & Sim & $85 \%$ & $100 \%$ & $98 \%$ \\
\hline & Não & $15 \%$ & $0,0 \%$ & $2 \%$ \\
\hline \multirow[t]{4}{*}{11} & Bom & $55 \%$ & $41 \%$ & $59 \%$ \\
\hline & Ruim & $1 \%$ & $41 \%$ & $0 \%$ \\
\hline & Ótimo & $29 \%$ & $18 \%$ & $18 \%$ \\
\hline & Regular & $15 \%$ & $0,0 \%$ & $23 \%$ \\
\hline \multirow[t]{2}{*}{12} & Sim & $79 \%$ & $70 \%$ & $75 \%$ \\
\hline & Não & $21 \%$ & $30 \%$ & $25 \%$ \\
\hline
\end{tabular}

Na tabela 2 onde foram expostos os resultados das questões 8 a 12 realizadas nas três escolas, foram questionados aos alunos se os mesmo gostariam de ter aulas de biologia ministradas em laboratórios, se eles achavam que as aulas práticas poderiam influenciar na melhora do aprendizado da biologia, se tinham o interesse em se tornarem professores de biologia. E como estes estudantes classificavam a matéria de ciências, e se gostavam desta disciplina.

Os resultados expressos pelos alunos das 3 escolas quanto a questão número 8 , que diz a respeito a necessidade dos alunos em aulas práticas de biologia em laboratório $98 \%$ dos estudantes responderem que gostariam de ter aulas práticas da matéria em laboratório. Na questão 9, que diz a respeito aos mesmos, entende-se que as aulas práticas de biologia poderia ser uma maneira de melhorar a compreensão do conteúdo da matéria, e 99\% responderam que sim. Com relação à questão 10 que diz a respeito se os alunos gostariam de ser professores de biologia, $97 \%$ dos mesmos responderam ter vontade.

O resultado da questão 11, que questionava como o estudante classifica a disciplina de biologia, 95\% classificaram a matéria como boa. Por fim na questão de número 12 que perguntava se os alunos gostavam da disciplina de biologia $87 \%$ dos alunos diz gostarem da matéria. Estes resultados estão de acordo com o encontrado por Lima e Garcia (2011) trabalho intitulado por Uma investigação sobre a importância das aulas práticas de biologia no ensino médio, que $95 \%$ dos alunos indicam que os mesmo consideram as aulas 
práticas como um objeto facilitador da aprendizagem, estando presente essa ideia até mesmo naqueles que nunca tiveram contato com esse tipo de aula.

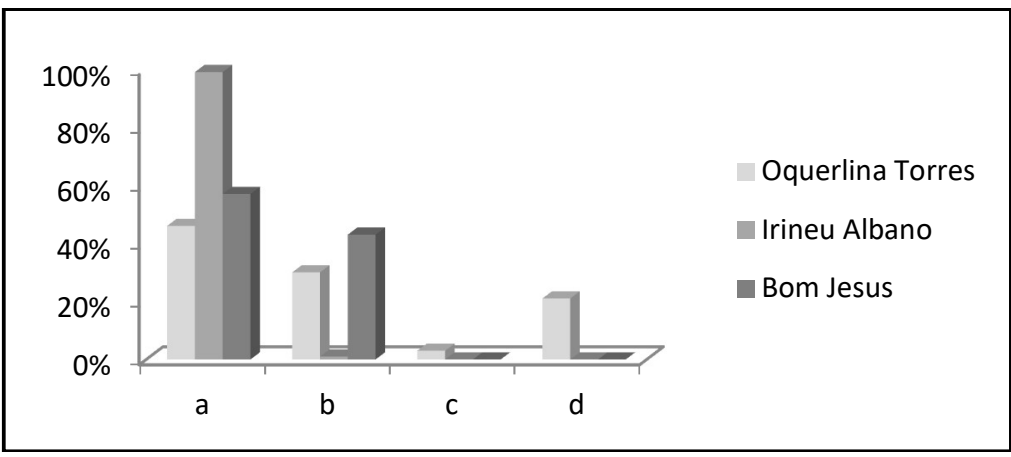

Figura 3. Expressão das respostas obtidas a partir dos questionários aplicados aos alunos dos 3 Colégios pesquisados sobre a concepção de biologia celular.

Por fim, na figura 3, onde foram expostos os resultados das 3 escolas da questão 13 foi questionado aos alunos qual a opinião dos mesmos pra que houvessem um auxilio no ensino das aulas práticas da disciplina de biologia, foi proposto questões de $\mathrm{A}$ há $\mathrm{D}$ que propunha como alternativa, laboratório, área experimental, material didático e aula de campo.

Os resultados expressos pelos alunos das 3 escolas quanto a questão número 13, que diz respeito de qual a melhor maneira de auxilio das aulas práticas da disciplina de biologia de acordo com o pensamento dos alunos, 92\% dos alunos responderam aulas práticas em laboratório poderiam auxiliar na melhoria das aulas praticas da matéria. Estes resultados estão de acordo com o encontrado por Lima e Garcia (2011), trabalho intitulado "Uma investigação sobre a importância das aulas práticas de biologia no ensino médio", que $95 \%$ dos alunos responderam gostar de aulas de biologia ministradas no laboratório de informática, alegando ser uma grande ferramenta para o melhor aprendizado dos estudantes.

É preciso que os responsáveis pelo ensino das escolas públicas, procurem meios para que os alunos possam vivenciar situações, que por via seja utilizada a informática como recurso educacional, com o objetivo relacionar o aprendizado e a informática, no qual o papel do educador nesta situação, é que esta metodologia seja mais adequada ao seu estilo de trabalho. Assim, o professor estará apto a desenvolver atividades correlacionadas à informática e educação e a assumir uma nova forma de educar na qual seja utilizado este método em educação (GIANOTTO et al., 2010)

A disciplina de biologia quando bem ministrada em sala de aula pode auxiliar os estudantes a encontrar respostas para diversas questões e fazer com que estejam em permanente exercício de raciocínio, que irá despertar o interesse e a busca progressiva pelo conhecimento. Com o objetivo de fornecer "escolas para todos", começaram a serem relacionados os conteúdos do ensino de biologia a vida diária e a experiência do aluno, isso exige uma nova compreensão do mundo, suas relações e demandas sociais. 0 trabalho desta disciplina exige o uso de metodologias alternativas e práticas diversificadas, que tem o foco em facilitar o aprendizado do aluno e aumentar o interesse em aprender mais (FEITOSA et al., 2010).

Portanto, entende-se que o educador que não procurar meios para despertar a curiosidade do aluno, ou ao menos o desejo em aprender aquilo que ele transmite, o processo ensino-aprendizagem não terá 
resultados positivos. Hoje em dia, é necessário que o ensino de biologia esteja focado em um aprendizado que apresente comprometimento com as questões sociais, politicas e econômicas, correlacionando a ciência, tecnologia e sociedade como um todo. Mas nota-se que, nos últimos anos, o ensino de biologia tem estado voltado para a transmissão de conteúdos, que geralmente é realizado por aulas expositivas onde o aluno deixa de ser o centro do ensino e aprendizagem e passar a ser apenas um receptor de informações. Poderia também ser um grande problema a forma com que é aprendido no ambiente escolar o que desfoca totalmente com a realidade dos alunos, isso pode ocasionar aulas de biologia sem sentido e irrelevante para a grande maioria dos discentes (NASCIMENTO et al., 2016).

\section{CONCLUSÕES}

Diante dos resultados encontrados no presente trabalho, concluiu-se que os professores das 3 unidades educacionais trabalhadas não utilizam com frequência matérias diversificados para a ministração de suas aulas, o que pode causar uma deficiência no aprendizado dos alunos. Com esta pesquisa, percebeuse a importância da utilização da informática, aulas práticas e outras, para o aprendizado dos alunos.

A melhor alternativa para modificar esse quadro seria a implementação por parte dos gestores educacionais, capacitações destinadas para professores de biologia que os incentivem a utilizar de aulas práticas e abordagem de seus conteúdos, pois é de grande relevância que estas aulas sejam utilizadas para o aprendizado da ciência, já que para uma formação positiva dos alunos, os mesmo precisam passar por experiências que correlacionem o campo teórico e assim desperte os alunos a curiosidade e interesse para investigar os diferentes componentes da natureza.

É necessário que a instituição foque no aprendizado por meio de conteúdos, planejamentos e orientações de atividades que possam garantir a transformação dos conceitos espontâneos em conceitos científicos. Sendo um aprendizado adequado e organizado irá resultar em um ensino de qualidade, que irá auxiliar o aluno em sua vida estudantil e pessoal. É necessário que os professores formulem estratégias para reconstruir os conhecimentos de seus alunos, focando em conhecimentos do dia a dia de cada aluno relacionado com a biologia, influenciando o aprendizado dos alunos, fortalecendo a sua identidade no intuito de abordar um conhecimento inovador.

\section{REFERÊNCIAS}

AUGUSTO, T. G. S; CALDEIRA, A. M. A.. Dificuldades para implantação ou práticas interdisciplinares em escola estadual, apontados por professores da área de ciência da natureza. Revista investigação em ensino de ciências, São Paulo, v.12, n.1, 2007.

BACRI, A. P. R.. Ensino de biologia na perspectiva dos alunos do ensino médio. Uberlândia, 2013.
BAPTISTA, G. C. S.; PINHEIROS, J. R.. Ensino de biologia e dialogo intercultural: possibilidades a partir de um conto. Florianópolis, 2017.

BÁRBARA, V. F.; MALAFAI, G.; RODRIGUES, A. S. L.. A análise das concepções e opiniões dos discentes sobre o ensino da biologia. Revista eletrônica de educação, São Carlos, v.4, n.2, 2010. 
BEJARANO, N. R. R.; CASTRO, D. R.. O perfil do conhecimento sobre seres vivos pelos estudantes da COOPEC: uma ferramenta para planejar o ensino de ciências. Revista Ensaio, Belo Horizonte, v.14, n.3, 2012.

BEZERRA, D. S.; MARQUES, J. A.; SOARES, A. M.. Concepções acerca da biologia entre discentes do ensino médio no município de Cajazeiras- Paraíba. Revista de pesquisa Interdisciplinar, Campina Grande, n.2, 2017.

BRANDOLIN, F.; KOSLINSKI, M. C.; SOARES, A. J. G.. A percepção dos alunos sobre a educação física no ensino médio. Revista educação Física, Rio de Janeiro, v.26, n.4, 2015.

CALISTO, P. S.. Discussão sobre contextualização no ensino da citologia considerando a percepção de alunos da educação de jovens e adultos. João Pessoa, 2015.

CASTRO, T. F; GOLDSCHMIDT, A. I.. Aulas práticas em ciências: concepções de estagiários em licenciatura em biologia e a realidade durante os estágios. Revista educação em ciências e matemática, Amazonas, v.13, n.25, 2016.

CHAER, G.; DINIZ, R. R. P.; RIBEIRO, E. A.. A técnica do questionário na pesquisa educacional. Revista Evidência, Araxá, v.7, n.7, 2011.

CONCEIÇÃO, M. S.; KONFLONZ, T. L.; PIGATTO, A. G. S.; ZBOROWSKI, C.A.. Percepção de alunos dos anos iniciais sobre seres vivos. Santa Maria, 2017. COUTINHO, C.; NASCIMENTO, T. E.. Metodologias ativas de aprendizagem e o ensino de ciências. Santiago, 2016.

DANTAS, S. M. M. M.; PARANHOS, J. D. N.; SILVA, J.S.; SOUSA, F.S.. As metodologias usadas por professores de ciências e biologia no processo de ensino/aprendizagem. Revista SREnBio, Piauí, n.7, 2014.

DEUS, M. S. M.; GONÇALVES, N. M. N.; MOURA, J.; PERON, A. P.. Biologia/genética: o ensino de biologia, com enfoque a genética, das escolas publicas no Brasil- breve relato e reflexão. Revista Sumina: ciências biológicas e da saúde, Londrina, v.34, n.2, 2017.

DIETRICH, F.; GERSTBERGER, A.; REMPEL, C; STROHSCHOEN, A. A. G.. Percepção de alunos de ciências biológicas sobre diferentes metodologias de ensino. Revista Signos, Lajeado, n.1, 2016.
DINIZ, R. E. S.; GIANOTTO, D. E. P.. Formação inicial de professores de biologia: a metodologia colaborativa mediado pelo computador e a aprendizagem para a docência. Revista ciência e educação, Bauru, v.16, n.3, 2010.

DINIZ, R. E. S.; OKADA, F. K.; POSSOBOM, C. C. F.. Atividades práticas de laboratórios no ensino de biologia e de ciências: relato de uma experiência. São Paulo, 2010.

FEITOSA, R. R.. O ensino de ciência/biologia: uma abordagem a partir da percepção de alunos do ensino fundamental. São Paulo, 2010.

FONSECA, S. G.. O trabalho do professor na sala de aula: relações ente sujeitos, saberes e práticas. Revista Brasileira Estudos Pedagógicos, Brasília, v.91, n.228, 2010.

GARCIA, R. N.; LIMA, D. B.. Uma investigação sobre a importância das aulas práticas de biologia no ensino médio. Revista cadernos da aplicação, Porto Alegre, v.24, n.1, 2011.

GIL, A. C.. Como elaborar projeto de pesquisa. 4 ed. São Paulo, 2002.

LAKATOS, E. M.; MARCONI, M. A.. Fundamentos de metodologia científica. 5 ed. São Paulo, 2003.

NETO, J. M.; TEIXEIRA, P. M. M.. O estado da arte da pesquisa em ensino de biologia no Brasil: um panorama baseado no índice de dissertações e teses. Revista eletrônica de ensenanza de las ciências, Jequié, v.11, n.2, 2012.

NICOLA, J. A.; PANIZ, C. M.. A importância da utilização de diferentes recursos didáticos no ensino de ciências e biologia. Revista Nead.São Paulo, v.2, n.1, 2016.

OLIVEIRA, J. C. P.. O questionário, o formulário e a entrevista como instrumentos de coleta de dados: vantagens e desvantagens do seu uso na pesquisa de campo em ciências humanas. Rio Grande do Norte, 2013.

PAIVA, A. S.. Conhecimentos tradicionais e ensino de biologia: desenvolvimento colaborativo de uma sequência didática sobre reprodução vegetal. Salvador, 2014. 